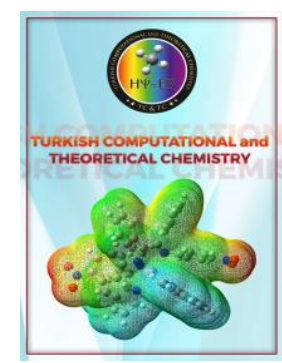

Received: 15.08.2020
Turkish Computational and Theoretical Chemistry

Turkish Comp Theo Chem (TC\&TC)

Volume (Issue): 4(2) - Year: 2020 - Pages: 76-87

e-ISSN: $2602-3237$

https://doi.org/10.33435/tcandtc. 781008

Accepted: 22.10 .2020

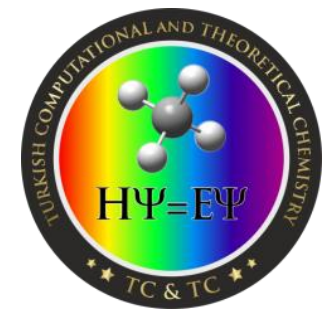

Research Article

\title{
Examination of anti-oxidant properties and molecular docking parameters of some compounds in human body
}

\author{
Burak Tüzün ${ }^{l}$ \\ Department of Chemistry, Faculty of Science, Sivas Cumhuriyet University, 58140 Sivas, Turkey
}

\begin{abstract}
:
There are many hormones and molecules in the human body. Many of these take place in different jobs and tasks. Some of these hormones are serotonin (A1), testosterone (A2), dopamine (A3), adrenaline (A4), methylcytosine (A5) and creatine (A6). The anti-oxidant properties of these molecules in both gas and water phases of the HF/6-31++G(d,p) basis set were calculated with the Gaussian package program. After this process, molecular docking calculations were made to compare the activities of molecules against proteins with anti-oxidant properties whose name are human peroxiredoxin-5 (HP5) and bovine xanthine oxidase (BXO), were compared.
\end{abstract}

Keywords: antioxidant, molecular docking, hormone, DFT, human body

\section{Introduction}

Some of the compounds in the human body turn into free radicals, which have a high activity during biochemical reactions. Due to the high probability of free radical activity, it causes many damages to a cell or organs. To minimize these damages, it is necessary to inhibit these free radicals. Previous studies have shown that anti-oxidant compounds have been shown to prevent many chronic diseases such as cancer and heart disease [1-7]. Today, it is seen that many herbal substances are claimed to have antimicrobial, antidiabetic, anti-inflammatory and antioxidant properties in the treatment of various diseases [8-15]. In this study, the antioxidant properties of many hormones in the human body will be examined. Their names are serotonin (A1), testosterone (A2), dopamine (A3), adrenaline (A4), methylcytosine (A5) and creatine (A6). The structures of molecules are given in Figure 1, 2, 3, 4, 5, and 6 .

Adrenaline [16] is both a hormone and a drug, it is also known as epinephrine. The hormone adrenaline (Epinephrine) is secreted in the core region of the adrenal glands in the human body. The task of this hormone in nature is to prepare the organism for emergency action. It shows its effect in the form of pulsation, the transfer of blood from the internal organs and the skin to the muscles, the change of glycogen in the liver to glucose, thereby providing an immediate source of energy. In case of excitement and fear, adrenaline secretion increases. It expands blood vessels. It reduces the feeling of pain.

However, Androstenedione [17] is an androgenic steroid that occurs mostly in the erectile gland, which, despite being directly ineffective, converts into testosterone. Androstenedion is a 19 carbon molecule in the steroid structure, found in the adrenal gland, testicles and ovaries.

Dopamine [18] is a naturally produced chemical in the body. In the brain, it acts as a neurotransmitter by activating dopamine receptors. Dopamine is also secreted from the hypothalamus and mixes with blood to act as a neurohormone. Its role as a

\footnotetext{
${ }^{1}$ Corresponding Authors

e-mail: btuzun@cumhuriyet.edu.tr; theburaktuzun@yahoo.com
} 
Burak Tüzün

neurohormone is to suppress the secretion of prolactin from the anterior lobe of the pituitary gland.

Serotonin (5-HT or 5-hydroxytryptamine) [19] is a neurotransmitter that gives a feeling of happiness, vitality and exhilaration in man. Depressive, tired, and bored mood is observed in the lack of human body. It is structurally included in the monoamine group and is synthesized from the tryptophan amino acid. When the chemical of serotonin is released in the brain, the blood vessels contract and contract; It expands as the level of serotonin decreases. The level of serotonin in the body is high before the migraine attack and it decreases after the attack.

Testosterone [20] is a steroid hormone from the androgen group. In mammals, testosterone is produced primarily in males, testicles in males and females in the ovaries. To a small extent, it is secreted from the adrenal glands. It is a male sex hormone.

Human Peroxiredoxin-5 (HP5) [21], mitochondrial is a protein that in humans is encoded by the HP5 gene. In human cells, it has been shown that HP5 can be localized to mitochondria, peroxisomes, cytosol. HP5 is identified by virtue of the sequence homologies to yeast peroxisomal antioxidant enzyme PMP20. On the other hand, bovine xanthine oxidase (BXO) [22] enzyme, this enzyme catalyzes the oxidation hypoxanthine to xanthine and can further catalyze the oxidation of xanthine to uric acid. This enzyme plays an important role in the catabolism of purines. Molecular docking calculations have been made using these two important anti-oxidant proteins.

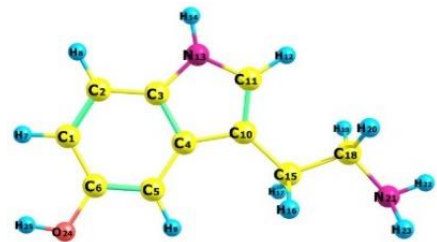

Figure 1. Atomic labeling of the serotonin molecule (A1)

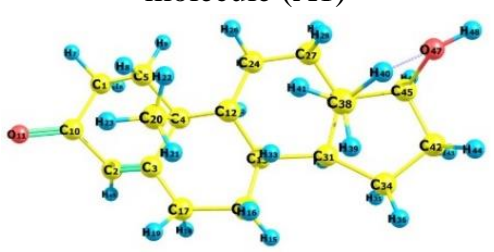

Figure 2. Atomic labeling of the testosterone molecule (A2)

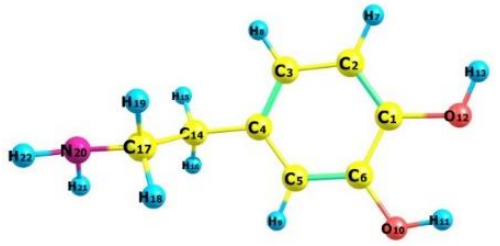

Figure 3. Atomic labeling of the dopamine molecule (A3)

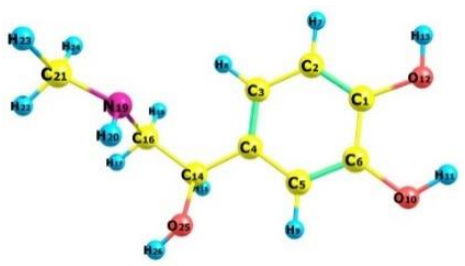

Figure 4. Atomic labeling of the adrenaline molecule (A4)

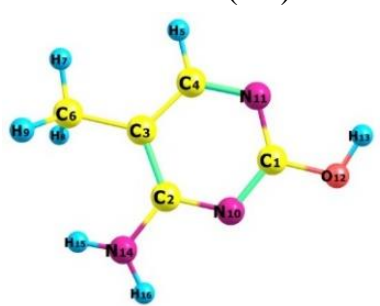

Figure 5. Atomic labeling of the methylcytosine molecule (A5)

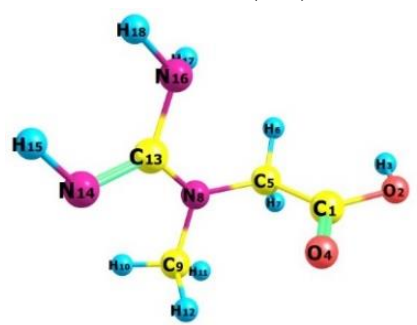

Figure 6. Atomic labeling of the creatine molecule (A6)

In this study, the anti-oxidant properties of the molecules were investigated by calculating the gas and water phase on the Hartree-Fock (HF)/6$31++\mathrm{G}(\mathrm{d}, \mathrm{p})$ basis set using the Gaussian package program. Subsequently, the activities of the molecules against Human peroxiredoxin 5 (HP5) (pdb ID: 1HD2) [21] and Bovine Xanthine Oxidase (BXO) (pdb ID: 3NRZ) [22] enzyme proteins were examined.

\section{Method}

\subsection{Gaussian study}

Theoretically, the process of comparing the antioxidant activities of molecules requires calculating more than one thermodynamic parameter. These thermodynamic parameters are bond dissociation 
Burak Tüzün

enthalpy (BDE), proton dissociation enthalpy (PDE), proton affinity (PA), ionization potential (IP) and electron transfer enthalpy (ETE) [23-27]. In this study, 3 mechanisms were examined in the anti-oxidant study. The first one is the hydrogen atom transfer mechanism (HAT).

$$
\mathrm{R}+\mathrm{AH} \rightarrow \mathrm{RH}+\mathrm{A}
$$

In this mechanism, the free radical molecule $\left(R^{*}\right)$ extracts a hydrogen from the anti-oxidant $(A H)$ and converts the anti-oxidant into its free radical form $\left(A H^{+}\right)$. To calculate the reactivity of the compound, it is necessary to calculate the bond dissociation enthalpy (BDE) of the A-H bond.

The second mechanism is single electron transferproton transfer (SET - PT). This mechanism consists of two consecutive reactions. In the first one, the removal of the electron from the $\mathrm{AH}$ occurs immediately after the proton transfer.

$$
\begin{aligned}
& R+A H \rightarrow R^{-}+A H^{+} . \\
& A H^{+} \rightarrow H^{+}+A^{.}
\end{aligned}
$$

These two mechanisms are ionization potential (IP) and proton dissociation enthalpy (PDE) from $\mathrm{AH}^{+}$. cation radical, respectively.

The mechanism of the third and last reaction is again in two stages. These two mechanisms are called the SPLET (Sequential proton loss electron transfer) mechanism.

$$
\begin{gathered}
A H \rightarrow A^{-}+H^{+} \\
A^{-}+H^{+}+R^{\cdot} \rightarrow A^{-}+R H
\end{gathered}
$$

The reaction enthalpy of the first reaction is the proton affinity (PA) of the anion. The reaction enthalpy of the second reaction is abstraction of electron, namely electron transfer enthalpy (ETE). The enthalpies of the reactions for these five reactions are calculated from the formulas below.

$$
\begin{gathered}
B D E=H\left(A^{\cdot}\right)+H\left(H^{\cdot}\right)-H(A H) \\
I P=H\left(A H^{+\cdot}\right)+\left(e^{-}\right)-H(A H) \\
P D E=H\left(A^{\cdot}\right)+H\left(H^{+}\right)-H\left(A H^{+\cdot}\right) \\
P A=H\left(A^{-}\right)+H\left(H^{+}\right)-H(A H) \\
E T E=H\left(A^{\cdot}\right)+H\left(e^{-}\right)-H\left(A^{-}\right)
\end{gathered}
$$

To calculate the numerical values in these formulas, GaussView 5.0.8, Gaussian09 AS64LG09RevD.01, [28,29] package programs were used. Calculations of anti-oxidant molecules were calculated in Hartree-Fock (HF) [30,31] with 6$31++\mathrm{G}(\mathrm{d}, \mathrm{p})$ basis set in the gas and water phase.
Besides, the gas phase enthalpies of the hydrogen atom, proton, and electron were $-0.49765,0.00236$, and 0.00118 hartree, respectively [32,33].

\subsection{Molecular docking}

In this study, molecular docking calculations to compare the biological activities of molecules were made using Maestro Molecular modeling platform (version 12.2) by Schrödinger. Proteins and molecules must be prepared for calculations. In the calculations, a different process is performed for the molecules at each stage. Firstly, it was used from Gaussian software program [29] to obtain optimized structures of molecules, which created files with the extension *.sdf using these structures. Using these files, all calculations were made with Maestro Molecular modeling platform (version 12.2) by Schrödinger, LLC [34]. Maestro Molecular modeling platform (version 12.2) by Schrödinger comes together from many modules. In the first module used, the protein preparation module $[35,36]$ was used to prepare the proteins for calculations. The crystal structures of these proteins have been downloaded from the protein data bank site. These proteins were initially minimized and water molecules in their crystal structures were removed. In the next step, the active regions of the proteins were determined for calculations, in which the proteins in this active region were given freedom of movement. Therefore, these proteins were enabled to interact with molecules more easily. In the next step, the LigPrep module [37,38] was used to prepare the working molecules for calculations.

Calculations were performed to find high energy isomers in physiological $\mathrm{pH}$ values of new cyanopyridine derivatives containing 3D structures and the correct protonation conditions. In the next step, the prepared protein and molecules were docked with each other. The Glide ligand docking module $[39,40]$ was used for this step. In this module, OPLS3e method was used in all calculations for docking calculations of molecule and proteins. The numerical value of many parameters obtained as a result of molecular docking calculations using this module is used.

\section{Result and discussion}

Theoretical studies are an important guide for experimental studies [41-45]. Because theoretical studies before experimental studies are used to 
Burak Tüzün

discover molecules with higher anti-oxidant properties. As a result of the theoretical calculations, a parameter and data about the molecules were obtained. In this way it was easier to design molecules with higher biological activity [46-47].

In this study, the anti-oxidant properties of the molecules in the human body were investigated. The anti-oxidant properties of these molecules were studied using the Gaussian package program. Many numerical values are obtained from the calculations made with the gaussian package program. These numerical values obtained are given in Table 1 .

For the anti-oxidant calculations of the molecules, it was done by removing hydrogen from the $\mathrm{OH}$ bond in the molecules. The parameters of all calculated anti-oxidant properties are given in Table 1 and 2. The parameters given in this table are calculated both in gas phase and water phase [25].
A molecule can have one $\mathrm{OH}$ bond or more $\mathrm{OH}$ bonds. The numerical value of BDE for the $\mathrm{OH}$ bond of the molecules is a parameter related to the HAT mechanism. The molecules with the numerical value of the smaller BDE parameter was found to have higher radical-scavenging activity. In the first step of the SET-PT mechanism, the IP value of these molecules is calculated. If a molecule has a lower IP value, it is known that the molecule has a higher ability to give electrons. In the second step of the SET-PT mechanism, PDE values are calculated. If a molecule has a lower PDE value, this means an easier reaction. Finally, the SPLET mechanism consists of two stages. In the first stage, PA parameter is calculated. if a molecule has a lower PA value, it indicates that the molecule has a higher proton affinity. In the second stage of SPLET, the ETE parameter is calculated. if a molecule has a lower ETE value, that molecule indicates an easier reaction [23-25].

Table 1. Anti-oxidant properties of Studies molecules in gas phase

\begin{tabular}{clcccccc} 
Molecule & Atom & BDE & IP & PDE & PA & ETE & Spin value \\
\hline A1 & O24-H & 46.28 & 141.43 & 219.35 & 361.64 & -0.86 & -0.406 \\
\hline A2 & O47-H & 69.03 & 165.67 & 217.87 & 375.56 & 7.97 & -0.500 \\
\hline \multirow{2}{*}{ A3 } & O10-H & 51.65 & 152.21 & 213.95 & 360.84 & 5.32 & -0.394 \\
& O12-H & 45.49 & 152.21 & 207.78 & 348.49 & 11.51 & -0.481 \\
\hline \multirow{2}{*}{ A4 } & O25-H & 120.87 & 146.40 & 288.96 & 370.54 & 64.82 & -0.796 \\
& O10-H & 50.02 & 146.40 & 218.12 & 363.33 & 1.20 & -0.394 \\
& O12-H & 43.83 & 146.40 & 211.92 & 349.18 & 9.14 & -0.486 \\
\hline A5 & O12-H & 68.52 & 163.26 & 219.77 & 355.57 & 27.45 & -0.324 \\
\hline A6 & O2-H & 81.34 & 152.23 & 243.60 & 329.24 & 66.60 & -0.626 \\
\hline
\end{tabular}

Table 2. Anti-oxidant properties of Studies molecules in water phase

\begin{tabular}{cllcccc} 
Molecule & Atom & BDE & IP & PDE & PA & ETE \\
\hline A1 & O24-H & 47.62 & 101.52 & 260.60 & 305.34 & 56.78 \\
\hline A2 & O47-H & 74.49 & 133.72 & 255.27 & 326.15 & 62.84 \\
\hline \multirow{2}{*}{ A3 } & O10-H & 49.80 & 109.90 & 254.40 & 303.55 & 60.74 \\
& O12-H & 47.27 & 109.90 & 251.87 & 298.89 & 62.88 \\
\hline \multirow{2}{*}{ A4 } & O25-H & 103.28 & 109.45 & 308.33 & 317.28 & 100.51 \\
& O10-H & 49.40 & 109.45 & 254.45 & 303.33 & 60.57 \\
& O12-H & 46.95 & 109.45 & 252.00 & 298.54 & 62.91 \\
\hline A5 & O12-H & 66.67 & 118.19 & 262.99 & 295.61 & 85.57 \\
\hline A6 & O2-H & 71.38 & 108.47 & 277.41 & 284.18 & 101.71 \\
\hline
\end{tabular}

As a result of the calculations made, spin densities were calculated to examine the charge density of the molecules. Spin density values of the molecules are given below the atoms in Figure 7, 8, 9, 10, 11, and 12. The lower spin density shown on the atoms in the molecule indicates higher delocalization. Consequently, higher delocalization means easier radical formation. Being more radical as a result of 
all these situations affects the stability of the radical and causes the formation of more stable radicals [25].

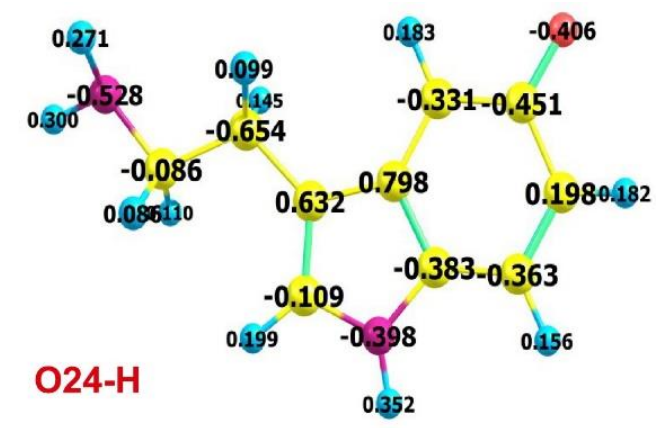

Figure 7. Spin density distributions of molecule

A1

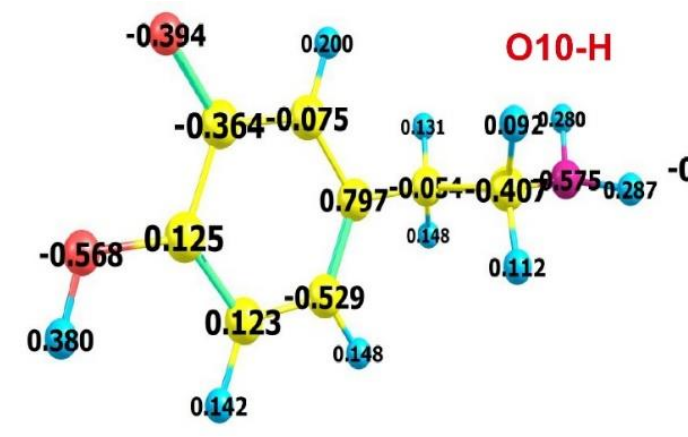

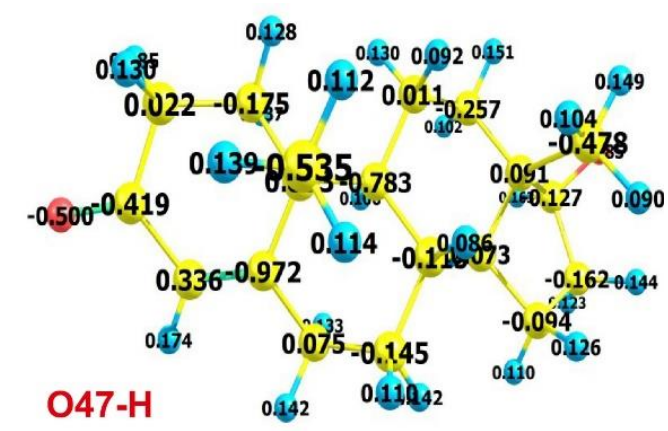

Figure 8. Spin density distributions of molecule

Figure 9. Spin density distributions of molecule A3

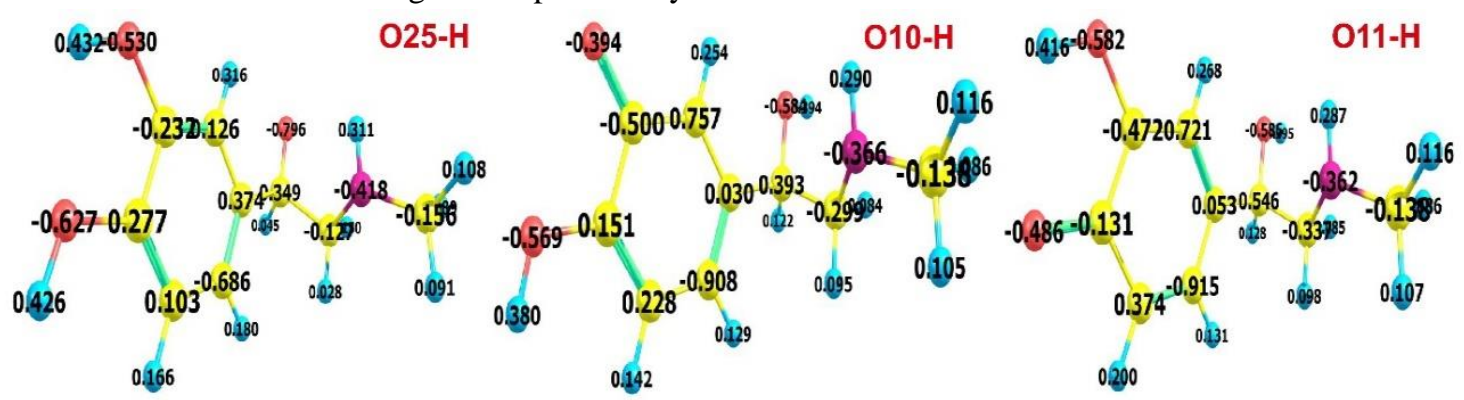

Figure 10. Spin density distributions of molecule A4

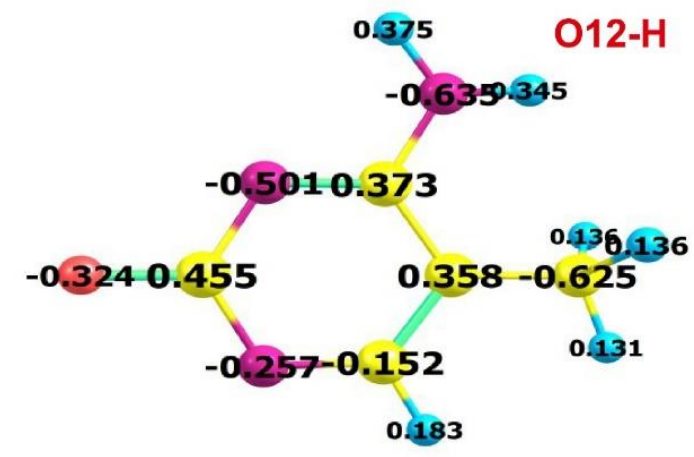

Figure 11. Spin density distributions of molecule

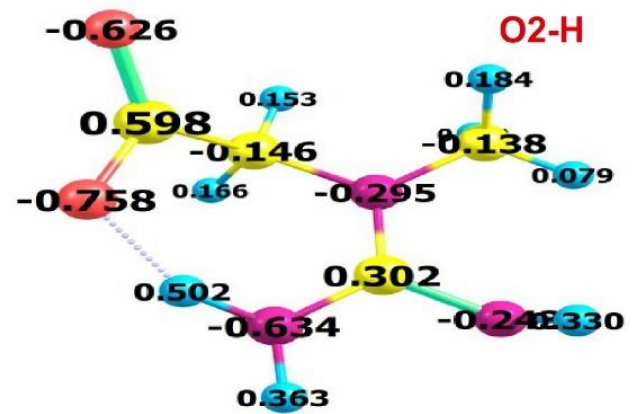

Figure 12. Spin density distributions of molecule A6 
Turkish Comp Theo Chem (TC\&TC), 4(2), (2020), 76-87

Burak Tüzün

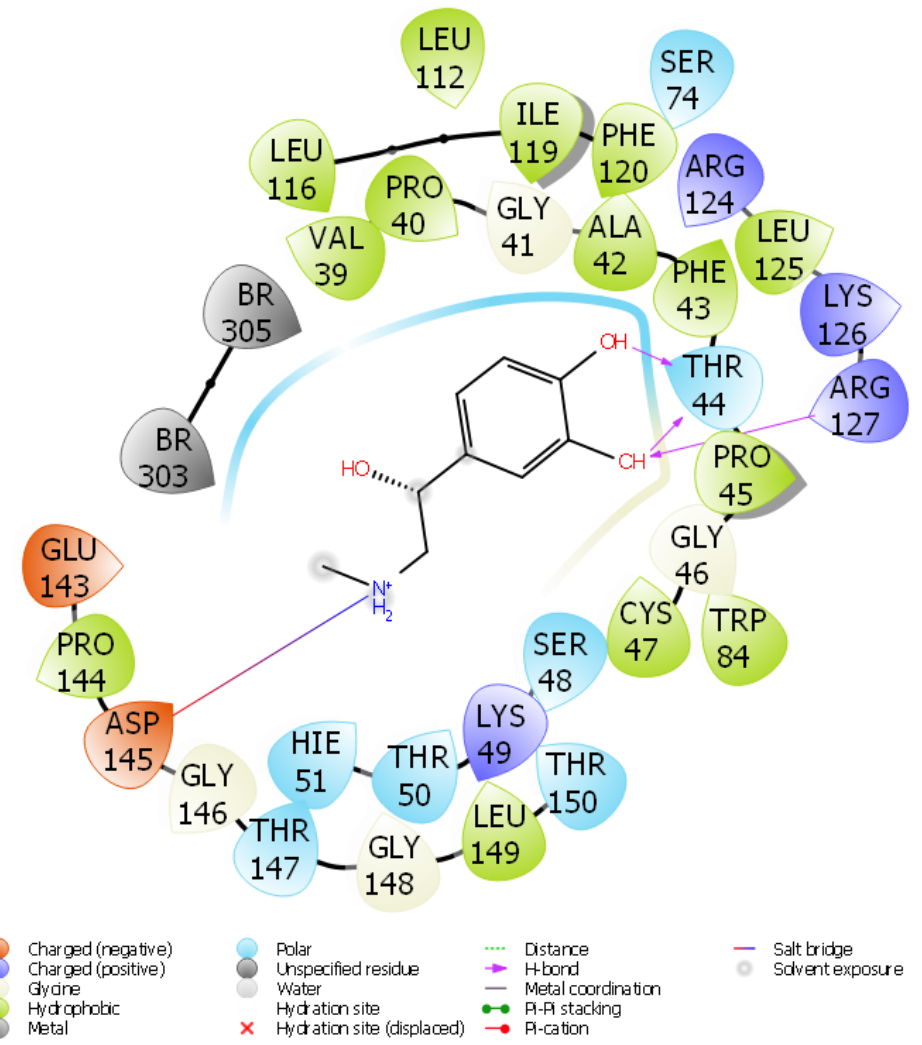

Figure 7. The interaction of the most active molecule with HP 5 proteins

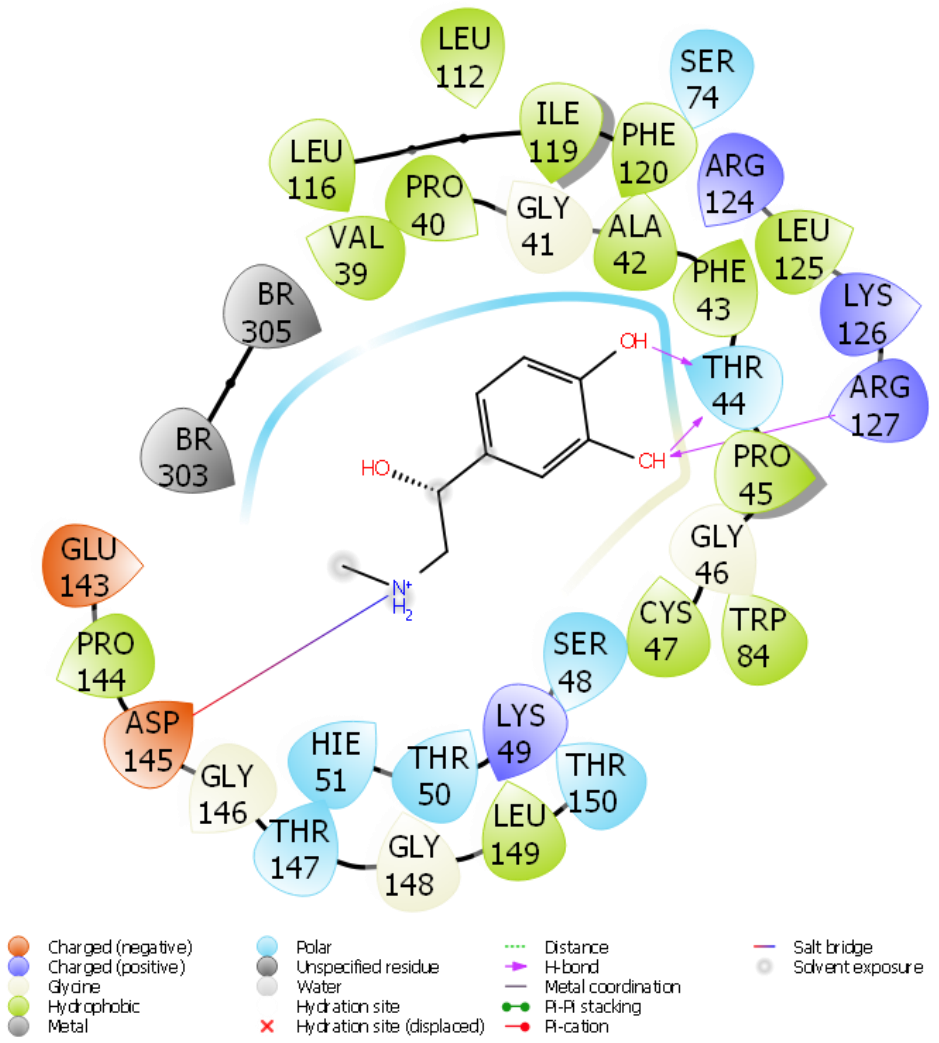

Figure 8 . The interaction of the most active molecule with $\mathrm{BXO}$ proteins 
Burak Tüzün

Among the theoretical calculations made, the most reliable and accurate method used to compare the activities of molecules is molecular docking [4850]. This method compares the activities of molecules with their interactions with proteins. As the interaction between molecule and protein increases, the activity of the molecule increases [51-53]. These interactions have many interactions such as hydrogen bonds, polar and hydrophobic interactions, $\pi-\pi$ and halogen [54-60]. These interactions are represented in Figure 13 and 14. Compared with molecular docking method to examine the anti-oxidant properties of molecules. Human peroxiredoxin 5 (HP5) (pdb ID: 1HD2) and Bovine Xanthine Oxidase (BXO) (pdb ID: 3NRZ) proteins were downloaded from the Protein Data Bank site for this comparison.

The parameters obtained for these molecules as a result of the calculations are given in Table 3 .
Among these parameters obtained as a result of the calculations, the most important parameter showing the activity is the docking score. The molecule with the most negative numerical value of this parameter has higher activity [61-64]. Apart from that, many parameters have been calculated from which information can be obtained about the activities of the molecules. Glide hbond, Glide evdw, and Glide ecoul parameters are used to explain the interactions between molecules and proteins. The parameters showing the numerical values of the interaction between the molecule and the enzyme are Glide hbond, Glide evdw, Glide ecoul. On the other hand, Glide emodel, Glide energy, Glide einternal, and Glide posenum parameters are the numerical values of the exposure formed between the molecule and protein [65-69].

Table 3. Numerical values of the docking parameters of molecule against enzymes

\begin{tabular}{cccccccc}
\hline Protein & Parameter & A1 & A2 & A3 & A4 & A5 & A6 \\
\hline & Docking score & -4.61 & -4.62 & -5.26 & -5.49 & -4.65 & -4.96 \\
& Glide ligand efficiency & -0.36 & -0.22 & -0.48 & -0.42 & -0.52 & -0.55 \\
& Glide hbond & -0.22 & -0.13 & 0.00 & -0.32 & -0.20 & -0.39 \\
HP 5 & Glide evdw & -15.39 & -19.41 & -10.36 & -12.65 & -14.79 & -7.21 \\
& Glide ecoul & -9.85 & -2.83 & -16.46 & -17.61 & -4.86 & -3.26 \\
& Glide emodel & -35.73 & -29.38 & -38.02 & -43.38 & -26.35 & -24.42 \\
& Glide energy & -25.24 & -22.24 & -26.82 & -30.27 & -19.65 & -10.47 \\
& Glide einternal & 1.53 & 0.00 & 5.80 & 7.03 & 0.00 & 1.34 \\
& Glide posenum & 368 & 169 & 398 & 73 & 304 & 119 \\
\hline BXocking score & -6.56 & -5.04 & -6.24 & -7.87 & -5.94 & -6.57 \\
& Glide ligand efficiency & -0.51 & -0.24 & -0.57 & -0.61 & -0.46 & -0.73 \\
& Glide hbond & -0.34 & -0.61 & -0.20 & -0.32 & -0.36 & -0.50 \\
& Glide evdw & -24.38 & -30.39 & -16.03 & -18.09 & -13.35 & -23.07 \\
& Glide ecoul & -9.81 & -7.20 & -18.91 & -23.34 & -21.41 & -10.59 \\
& Glide emodel & -55.23 & -48.94 & -50.72 & -61.12 & -50.45 & -46.34 \\
& Glide energy & -34.19 & -37.58 & -34.94 & -41.43 & -34.75 & -33.65 \\
& Glide einternal & 2.07 & 0.63 & 1.06 & 3.87 & 2.17 & 0.00 \\
Glide posenum & 334 & 75 & 361 & 340 & 109 & 267 \\
\hline
\end{tabular}

\section{CONCLUSIONS}

As a result of the theoretical calculations made, the most active molecule in terms of both anti-oxidant activity and molecular docking calculations among these six molecules was the adrenaline numbered A4. These results showed that both the anti-oxidant properties of the molecules were examined and it was calculated that the molecule adrenaline had the best activity against the anti-oxidant proteins.

\section{Acknowledgments}

This work is supported by the Scientific Research Project Fund of Sivas Cumhuriyet University under the project number RGD-020. This research was made possible by TUBITAK ULAKBIM, High Performance and Grid Computing Center (TR-Grid e-Infrastructure).

\section{References}

[1] N.F. Boyd and V.McGuire, The possible role of lipid peroxidation in breast cancer risk. Free Radical Biology and Medicine, 10(3-4) (1991) 185-190.

[2] P. Knekt, A. Reunanen, H. Takkunen, A. Aromaa, M. Heliovaara, and T. Hakuunen, Body iron stores and risk of cancer. International journal of cancer, 56(3) (1994) 379-382. 
[3] G.S. Omenn, G.E.Goodman, M.D. Thornquist, J. Balmes, M.R. Cullen, A. Glass, J.P. Keogh, F.L. Meyskens, B. Valanis, J.H. Williams, S. Barnhart, and S. Hammar, Effects of a combination of beta carotene and vitamin A on lung cancer and cardiovascular disease. New England journal of medicine, 334(18) (1996) 11501155.

[4] M. Valko, C.J. Rhodes, J. Moncola, M. Izakovic, and M. Mazura, Free radicals, metals and antioxidants in oxidative stressinduced cancer. Chemico-biological interactions, 160(1) (2006) 1-40.

[5] D.A. Street, G. Comstock, R. Salkeldy, and M. Klag, Serum antioxidants and myocardial infarction. Are low levels of carotenoids and alpha-tocopherol risk factors for myocardial infarction?. Circulation, 90(3) (1994) 1154-1161.

[6] L.H. Kushi, A.R. Folsom, R.J. Prineas, P.J. Mink, Y. Wu, and R. Bostick, N. Engl. Dietary antioxidant vitamins and death from coronary heart disease in postmenopausal women. New England Journal of Medicine, 334(18) (1996) 1156-1162.

[7] U. Singh and I. Jialal, Oxidative stress and atherosclerosis. Pathophysiology, 13(3) (2006) 129-142.

[8] Q. Huang, G.D. Lu, H.M. Shen, M.C.M. Chung, and C.N. Ong, Anti-cancer properties of anthraquinones from rhubarb. Medicinal research reviews, 27(5) (2007) 609-630.

[9] S. Ghosh, M.D. Sarma, A. Patra, and B. Hazra, Anti-inflammatory and anticancer compounds isolated from Ventilago madraspatana Gaertn., Rubia cordifolia Linn. and Lantana camara Linn. Journal of pharmacy and pharmacology, 62(9) (2010) 1158-1166.

[10] J.D.D. Tamokou, M.F. Tala,H.K.Wabo, J.R. Kuiate, and P. Tane, Antimicrobial activities of methanol extract and compounds from stem bark of Vismia rubescens. Journal of ethnopharmacology, 124(3) (2009) 571575.

[11] D.O. Andersen, N.D. Weber, S.G. Wood, B.G. Hughes, B.K. Murray, and J.A. North, In vitro virucidal activity of selected anthraquinones and anthraquinone derivatives. Antiviral research, 16(2) (1991) 185-196.

[12] H. Hussain, A. Al-Harrasi, A. Al-Rawahi, I.R. Green, R. Csuk, I. Ahmed, A. Shah, G. Abbas, N.U. Rehman, R. Ullah, In vitro virucidal activity of selected anthraquinones and anthraquinone derivatives. Antiviral research, 16(2) (1991) 185-196.

[13] G.C. Yen, P.D. Duh, and D.Y. Chuang, Antioxidant activity of anthraquinones and anthrone. Food chemistry, 70(4) (2000) 437441.

[14] S.K. Agarwal, S.S. Singh, S. Verma, and S. Kumar, Antifungal activity of anthraquinone derivatives from Rheum emodi. Journal of ethnopharmacology, 72(1-2) (2000) 43-46.

[15] D. Kremer, I. Kosalec, M. Locatelli, F. Epifano, S. Genovese, G. Carlucci, and M.Z. Kon 'ci'c, Anthraquinone profiles, antioxidant and antimicrobial properties of Frangula rupestris (Scop.) Schur and Frangula alnus Mill. bark. Food Chemistry, 131(4) (2012) 1174-1180.

[16] H.F. Brown, D. DiFrancesco, S.J. Noble, How does adrenaline accelerate the heart?. Nature, 280(5719) (1979) 235-236.

[17] H.L. Judd, S.S. Yen, Serum androstenedione and testosterone levels during the menstrual cycle. The Journal of Clinical Endocrinology \& Metabolism, 36(3) (1973) 475-481.

[18] P. Seeman, H.H. Van Tol, Dopamine receptor pharmacology. Trends in pharmacological sciences, 15(7) (1994) 264-270.

[19] H. Sternbach, The serotonin syndrome. Am J Psychiatry, 148(6) (1991) 705-713.

[20] E. Nieschlag, H.M. Behre, S. Nieschlag, Testosterone: action, deficiency, substitution. Cambridge University Press(2012).

[21] J.P. Declercq, C. Evrard, A. Clippe, D. Vander Stricht, A. Bernard, B. Knoops, Crystal structure of human peroxiredoxin 5, a novel type of mammalian peroxiredoxin at $1.5 \AA$ resolution. Journal of molecular biology, 311(4) (2001) 751-759. 
[22] H. Cao, J.M. Pauff, R. Hille, Substrate orientation and catalytic specificity in the action of xanthine oxidase the sequential hydroxylation of hypoxanthine to uric acid. Journal of Biological Chemistry, 285(36) (2010) 28044-28053.

[23] Z. Marković, S. Jeremić, J.D. Marković, M.S. Pirković, D. Amić, Influence of structural characteristics of substituents on the antioxidant activity of some anthraquinone derivatives. Computational and Theoretical Chemistry, 1077 (2016) 2531.

[24] S. Sari, B. Barut, A. Özel, D. Şöhretoğlu, Tyrosinase inhibitory effects of Vinca major and its secondary metabolites: Enzyme kinetics and in silico inhibition model of the metabolites validated by pharmacophore modelling. Bioorganic chemistry, 92 (2019) 103259.

[25] E. Koç, A. Üngördü, F. Candan, Antioxidant properties of methanolic extract of 'Veronica multifida'and DFT and HF analyses of its the major flavonoid component. Journal of Molecular Structure, 1197 (2019) 436-442.

[26] A. Urbaniak, M. Szeląg, M. Molski, Theoretical investigation of stereochemistry and solvent influence on antioxidant activity of ferulic acid. Computational and Theoretical Chemistry, 1012 (2013) 33-40.

[27] R. Kheirabadi, M. Izadyar, Antioxidant activity of selenenamide-based mimic as a function of the aromatic thiols nucleophilicity, a DFT-SAPE model. Computational biology and chemistry, 75(2018) 213-221.

[28] R. Dennington, T. Keith, J. Millam, GaussView, Version 6, Semichem Inc., Shawnee Mission, KS (2016)

[29] Gaussian 09, Revision D.01, M. J. Frisch, G.W. Trucks, H.B. Schlegel, G.E. Scuseria, M.A. Robb, J.R. Cheeseman, G. Scalmani, V. Barone, B. Mennucci, G.A. Petersson, H. Nakatsuji, M. Caricato, X. Li, H.P. Hratchian, A.F. Izmaylov, J. Bloino, G. Zheng, J.L. Sonnenberg, M. Hada, M. Ehara, K. Toyota, R. Fukuda, J. Hasegawa, M. Ishida, T. Nakajima, Y. Honda, O. Kitao, H. Nakai, T. Vreven, J.A. Montgomery, Jr.,
J.E. Peralta, F. Ogliaro, M. Bearpark, J.J. Heyd, E. Brothers, K.N. Kudin, V.N. Staroverov, R. Kobayashi, J. Normand, K. Raghavachari, A. Rendell, J. C. Burant, S.S. Iyengar, J. Tomasi, M. Cossi, N. Rega, J.M. Millam, M. Klene, J. E. Knox, J. B. Cross, V. Bakken, C. Adamo, J. Jaramillo, R. Gomperts, R. E. Stratmann, O. Yazyev, A.J. Austin, R. Cammi, C. Pomelli, J.W. Ochterski, R.L. Martin, K. Morokuma, V.G. Zakrzewski, G.A. Voth, P. Salvador, J.J. Dannenberg, S. Dapprich, A. D. Daniels, Ö. Farkas, J.B. Foresman, J.V. Ortiz, J. Cioslowski, and D.J. Fox, Gaussian, Inc., Wallingford CT, 2009.

[30] D. Vautherin, D.M. Brink, Hartree-Fock calculations with skyrme's interaction. I. Spherical nuclei, Phys. Rev. C, 5 (1972) 626-647

[31] A.D. Becke, Density-functional thermochemistry. III. The role of exact exchange, J. Chem. Phys., 98 (1993) 56485652

[32] J.S. Wright, E.R. Johnson, G.A. DiLabio, Predicting the activity of phenolic antioxidants: theoretical method, analysis of substituent effects, and application to major families of antioxidants. Journal of the American Chemical Society, 123-6 (2001) 1173-1183.

[33] J.E. Bartmess, Thermodynamics of the electron and the proton. The Journal of Physical Chemistry, 98-25 (1994) 64206424.

[34] L. Schrodinger, (2019). Small-Molecule Drug Discovery Suite 2019-4

[35] Schrödinger Release 2019-4: Protein Preparation Wizard; Epik, Schrödinger, LLC, New York, NY, 2016; Impact, Schrödinger, LLC, New York, NY, 2016; Prime, Schrödinger, LLC, New York, NY, 2019.

[36] R.A. Friesner, R.B. Murphy, M.P. Repasky, L.L. Frye, J.R. Greenwood, T.A. Halgren, P.C. Sanschagrin, D.T. Mainz, Extra precision glide: Docking and scoring incorporating a model of hydrophobic enclosure for protein-ligand complexes. Journal of medicinal chemistry. 49 (2006) 6177-6196. 
[37] G.M. Sastry, M. Adzhigirey, T. Day, R. Annabhimoju, W. Sherman, Protein and ligand preparation: parameters, protocols, and influence on virtual screening enrichments. Journal of computer-aided molecular design, 27(3) (2013) 221-234.

[38] Schrödinger Release 2019-4: LigPrep, Schrödinger, LLC, New York, NY, 2019.

[39] D. Kisa, N. Korkmaz, P. Taslimi, B. Tuzun, Ş. Tekin, A. Karadag, F. Şen, Bioactivity and molecular docking studies of some nickel complexes: New analogues for the treatment of Alzheimer, glaucoma and epileptic diseases. Bioorganic chemistry, 101 (2020) 104066.

[40] F. Türkan, P. Taslimi, S.M. Abdalrazaq, A. Aras, Y. Erden, H.U. Celebioglu, B. Tüzün, M.S. Ağırtaş, İ. Gülçin, Determination of anticancer properties and inhibitory effects of some metabolic enzymes including acetylcholinesterase, butyrylcholinesterase, alpha glycosidase of some compounds with molecular docking study. Journal of Biomolecular Structure and Dynamics (2020) 1-17.

[41] H.G. Bilgiçli, A.T. Bilgiçli, A. Günsel, B. Tüzün, D. Ergön, M.N. Yarasir, M. Zengin, Turn-on fluorescent probe for $\mathrm{Zn} 2+$ ions based on thiazolidine derivative. Applied Organometallic Chemistry, 34(6) (2020) e5624.

[42] S. Akkoç, B. Tüzün, İ.Ö. İlhan, M. Akkurt, Investigation of structural, spectral, electronic, and biological properties of 1, 3disubstituted benzimidazole derivatives. Journal of Molecular Structure, (2020) 128582 .

[43] L.K. Ojha, B. Tüzün, J. Bhawsar, Experimental and Theoretical Study of Effect of Allium sativum Extracts as Corrosion Inhibitor on Mild Steel in $1 \mathrm{M}$ $\mathrm{HCl}$ Medium. Journal of Bio-and TriboCorrosion, 6(2) (2020) 1-10.

[44] M. Akin, A. Günsel, A.T. Bilgiçli, B. Tüzün, G. Arabaci, N. Şaki, M.N. Yarasir, The Water-Soluble Peripheral Substituted Phthalocyanines as Corrosion Inhibitors for Copper in $0.1 \mathrm{~N} \mathrm{HCl}$ : Gravimetric, Electrochemical, SEM-EDS, and Quantum Chemical Calculations. Protection of Metals and Physical Chemistry of Surfaces, 56(3) (2020) 609-618.

[45] D. Douche, H. Elmsellem, L. Guo, B. Hafez, B. Tüzün, A. El Louzi, K. Bougrina, K. Karrouchi, B. Himmi, Anti-corrosion performance of 8-hydroxyquinoline derivatives for mild steel in acidic medium: Gravimetric, electrochemical, DFT and molecular dynamics simulation investigations. Journal of Molecular Liquids, (2020) 113042.

[46] A. Urbaniak, M. Szeląg, M. Molski, Theoretical investigation of stereochemistry and solvent influence on antioxidant activity of ferulic acid. Computational and Theoretical Chemistry, 1012 (2013) 33-40.

[47] R. Kheirabadi, M. Izadyar, Antioxidant activity of selenenamide-based mimic as a function of the aromatic thiols nucleophilicity, a DFT-SAPE model. Computational biology and chemistry, 75 (2018) 213-221.

[48] B. Tüzün, E. Saripinar, Molecular docking and 4D-QSAR model of methanone derivatives by electron conformationalgenetic algorithm method. Journal of the Iranian Chemical Society, 17 (2020) 9851000 .

[49] B. Tüzün, Investigation of pyrazoly derivatives schiff base ligands and their metal complexes used as anti-cancer drug. Spectrochimica Acta Part A: Molecular and Biomolecular Spectroscopy, 227 (2020) 117663.

[50] B. Tüzün, Investigation of the Molecules Obtained from Marijuana: Computational Study of Spectral, Structural and Docking 16(3,4) (2020) 59-74.

[51] H.U. Celebioglu, Y. Erden, F. Hamurcu, P. Taslimi, O.S. Şentürk, Ü.Ö. Özmen, B. Tüzün, İ. Gulçin, Cytotoxic effects, carbonic anhydrase isoenzymes, $\alpha$-glycosidase and acetylcholinesterase inhibitory properties, and molecular docking studies of heteroatom-containing sulfonyl hydrazone derivatives. Journal of Biomolecular Structure and Dynamics, (2020) 1-12.

[52] H.G. Bilgicli, P. Taslimi, B. Akyuz, B. Tuzun, I. Gulcin, Synthesis, characterization, biological evaluation, and 
Burak Tüzün

molecular docking studies of some piperonyl-based 4-thiazolidinone derivatives. Archiv der Pharmazie, 353(1) (2020) 1900304.

[53] H.G. Bilgiçli, D. Ergön, P. Taslimi, B. Tüzün, İ.A. Kuru, M. Zengin, İ. Gülçin, Novel Propanolamine Derivatives Attached to 2-Metoxifenol Moiety: Synthesis, Characterization, Biological Properties, and Molecular Docking Studies. Bioorganic Chemistry, (2020) 103969.

[54] K. Sayin, A. Üngördü, Investigations of structural, spectral and electronic properties of enrofloxacin and boron complexes via quantum chemical calculation and molecular docking. Spectrochimica Acta Part A: Molecular and Biomolecular Spectroscopy, 220 (2019) 117102.

[55] K. Sayin, D. Karakaş, Investigation of structural, electronic properties and docking calculations of some boron complexes with norfloxacin: A computational research. Spectrochimica Acta Part A: Molecular and Biomolecular Spectroscopy, 202 (2018) 276-283.

[56] K. Sayin, D. Karakaş, Quantum chemical investigation of levofloxacin-boron complexes: a computational approach. Journal of Molecular Structure, 1158 (2018) 57-65.

[57] K. Sayin, A. Üngördü, Investigation of anticancer properties of caffeinated complexes via computational chemistry methods. Spectrochimica Acta Part A: Molecular and Biomolecular Spectroscopy, 193 (2018) 147-155.

[58] K. Sayin, D. Karakaş, Determination of structural, spectral, electronic and biological properties of tosufloxacin boron complexes and investigation of substituent effect. Journal of Molecular Structure, 1146 (2017) 191-197.

[59] R. Jayarajan, R. Satheeshkumar, T. Kottha, S. Subbaramanian, K. Sayin, G. Vasuki, Water mediated synthesis of 6-amino-5cyano-2-oxo-N-(pyridin-2-yl)-4-(p-tolyl)$2 \mathrm{H}$-[1, 2'-bipyridine]-3-carboxamide and 6amino-5-cyano-4-(4-fluorophenyl)-2-oxo$\mathrm{N}$-(pyridin-2-yl)-2H-[1, 2'-bipyridine $]-3$ carboxamide-An experimental and computational studies with non-linear optical (NLO) and molecular docking analyses. Spectrochimica Acta Part A: Molecular and Biomolecular Spectroscopy, 229 (2020) 117861.

[60] A. Üngördü, K. Sayin, Quantum chemical calculations on sparfloxacin and boron complexes. Chemical Physics Letters, 733 (2019) 136677.

[61] A. Huseynova, R. Kaya, P. Taslimi, V. Farzaliyev, X. Mammadyarova, A. Sujayev, B. Tüzün, U.M. Kocyigit, S. Alwasel, İ. Gulçin. Design, synthesis, characterization, biological evaluation, and molecular docking studies of novel 1, 2aminopropanthiols substituted derivatives as selective carbonic anhydrase, acetylcholinesterase and $\alpha$-glycosidase enzymes inhibitors. Journal of Biomolecular Structure and Dynamics, (2020) 1-13.

[62] A. Aktaş, B. Tüzün, R. Aslan, K. Sayin, H. Ataseven, New anti-viral drugs for the treatment of COVID-19 instead of favipiravir, Journal of Biomolecular Structure and Dynamics, (2020) 1-11.

[63] A. Aktaş, B. Tüzün, A.H. Taşkin Kafa, K. Sayin, H. Ataseven, clarification of interaction mechanism of arbidol with covid-19 and investigation of the inhibition activity analogues against covid-19, Bratislava Medical Journal 121 (2020) 705711.

[64] M.A. Gedikli, B. Tüzün, A. Aktaş, K. Sayin, H. Ataseven, do clarithromycin, azithromycin and their analogues effective in the treatment of COVID-19? Bratislava Medical Journal, 122 (2021).

[65] P. Taslimi, Y. Erden, S. Mamedov, L. Zeynalova, N. Ladokhina, R. Tas, B. Tüzün, A. Sujayev, N. Sadeghian, S.H. Alwasel, I. Gulcin, The Biological Activities, Molecular Docking Studies, and Anticancer Effects of 1-Arylsuphonylpyrazole Derivatives. Jounal of Biomolecular Structure and Dynamics, (2020) 1-20.

[66] Y. Demir, P. Taslimi, Ü.M. Koçyiğit, M. Akkuş, M.S. Özaslan, H.E. Duran, Y. Budak, B. Tüzün, M.B. Gürdere, M. Ceylan, S. Taysi, I. Gülçin, Ş. Beydemir, Determination of the inhibition profiles of 
pyrazolyl-thiazole derivatives against aldose reductase and $\alpha$-glycosidase and molecular docking studies. Archiv der Pharmazie, (2020) e2000118.

[67] S. Kaya, S. Erkan, D. Karakaş, Computational investigation of molecular structures, spectroscopic properties and antitumor-antibacterial activities of some Schiff bases. Spectrochimica Acta Part A: Molecular and Biomolecular Spectroscopy, 244 (2020) 118829.

[68] E. Güzel, Ü.M. Koçyiğit, P. Taslimi, İ. Gülçin, S. Erkan, M. Nebioğlu, ... \& İ. Şişman, Phthalocyanine complexes with (4isopropylbenzyl) oxy substituents: preparation and evaluation of anti-carbonic anhydrase, anticholinesterase enzymes and molecular docking studies. Journal of Biomolecular Structure and Dynamics, (2020) 1-9.

[69] S. Ökten, A. Aydın, Ü.M. Koçyiğit, O. Çakmak, S. Erkan, C.A. Andac, ... İ. Gülçin, Quinoline-based promising anticancer and antibacterial agents, and some metabolic enzyme inhibitors. Archiv der Pharmazie, 353(9) (2020) 2000086. 